recommendation was made. But now a third group is tentatively going beyond saying that gp120 is ineffective: they are voicing the fear that it may be dangerous. Although it is realistic to expect people to become infected in the course of a clinical trial - that is, after all, intrinsic to the nature of a trial - they argue that someone should be asking why these particular breakthroughs happened. Is it because people believe that, after being vaccinated, they are 'protected' and thus can safely engage in more risky behaviour? If so, that suggests that the current trial protocols have an adverse effect on the control of the epidemic, that is, the limited efficacy of a vaccine may be overcome by the increased risktaking of the vaccinees, underscoring the need for more effective behavioural intervention. They point out that by determining the behaviour of infected trial participants around the time of vaccination it would be possible to determine whether behavioural changes played a role in infection. "It's like DNA evidence: We can't prove that behaviour led to the infection, but we can rule it out if it didn't," said one behavioural researcher who expressed concern about the current structure of vaccine trials.

A more frightening possibility is that there may be a biological basis for the breakthroughs, that is, the vaccine may somehow be enhancing the possibility of infection. This could be a disastrous thing in a country already racked with high infection rates. Researchers who raise this spectre quickly add that there is not strong, or even moderate, evidence for this, but insist that there is enough suggestive data, including the breakthrough infections, to make this a concern that must be addressed. When asked about the possibility, Fauci states emphatically that it is only a theoretical possibility right now, but adds that "it shouldn't be dismissed and it is something that should be looked at." However, he also says that "I think it is taking it a step too far at this point to say that not only doesn't this [gp120 vaccination] help, but it is also bad for you."

The debate over gp120 will likely become more open, more pointed and more loud when the data on the breakthrough infections are fully presented, gaining in intensity as large-scale trials in other countries draw closer.

FINTAN R. STEELE

\title{
Courts favour HIV compensation
}

Six years after the case began, the Tokyo and Osaka district courts recommended in early October that the Japanese government and five pharmaceutical companies pay $¥ 45$ million (US $\$ 448,000$ ) in compensation to each of 219 haemophiliacs who were infected with the human immunodeficiency virus (HIV) after using contaminated blood products (Nature Medicine 1, 396; 1995). The blood products were imported from the United States during the mid-1980s.

The court's recommendation brings an urgently needed settlement one step nearer to closure for the haemophiliacs (and their families). Ninety-one of the haemophiliacs have already died of AIDS since their cases were first brought in October 1989. They claimed that the government and the pharmaceutical companies were negligent in not acting swiftly enough to approve and supply blood products that had been heattreated to kill the virus.

The courts recommended a settlement plan to the defendants, which urges the

Japanese government and the pharmaceutical companies to accept responsibility and to split the costs. They suggested that the government pays 40 percent of the total compensation package and the five pharmaceutical companies - Green Cross Corporation, Chemo Sero Therapeutic Research Institute, Baxter Limited, Bayer Yakuhin Limited and Nippon Zoki Pharmaceutical Company - pay the rest. The plaintiffs had requested $\$ 1.14$ million in compensation each.

The government is expected to accept the so-called compromise plan, which would enable the plaintiffs to receive compensation quickly, without the government having to acknowledge its legal responsibility in the cases.

Haemophiliacs infected with HIV and their supporters held a rally in Tokyo after the courts announced their decision, where they called on the government and the companies to admit responsibility and to apologize.

RICHARD NATHAN Tokyo

\section{No link between needle exchange programmes and increased drug use}

A major new study has concluded that needle exchange programmes reduce the spread of HIV without increasing illegal drug use, a finding that is likely to put new pressure on the Clinton administration to support federal funding for these efforts.

The study, conducted by a joint panel of the US National Research Council and the Institute of Medicine, recommended that federal funds be made available to communities who seek to establish such programmes. The panel studied the experience of numerous programmes operating in the United States, as well as in Europe, Canada and Australia.

Since 1988, Congress has passed a series of statutes specifically prohibiting or restricting the use of federal funds to support needle exchange programmes. The language of the legislation provides that the ban remain in effect unless the Surgeon General determines that such programmes are effective and do not promote illegal drug use.

Many in the public health community have supported needle exchange programmes, but they are often opposed by

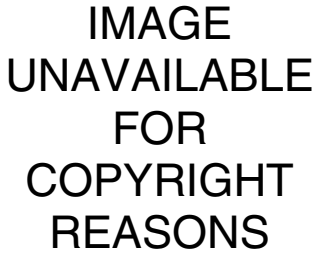

US panel urges federal support of needle exchange programmes to stem spread of HIV.

law enforcement organizations and others who view them as condoning, or even encouraging, illegal drug use.

The panel acknowledged that "the act of giving a needle to an injection drug user has a powerful symbolism that has sparked fears about the potential negative effects of needle exchange programs." However, it added: "There is no credible evidence to date that drug use is increased ... as a result of programs that provide legal access to sterile equipment."

MARLENE CIMONS Washington, $D C$ 